\title{
Technical Medicine: Designing Medical Technological Solutions for Improved Health Care
}

\author{
Marleen Groenier $^{1} \cdot$ Jules M. Pieters $^{2} \cdot$ Heleen A. T. Miedema ${ }^{1}$
}

Published online: 28 July 2017

(C) The Author(s) 2017. This article is an open access publication

\begin{abstract}
\section{Introduction}

Complex medical technology is rapidly being introduced in health care, aimed at improving diagnosis and treatment. However, mistakes in the use of medical technology show that adequate expertise to apply it safely is often lacking, let alone to improve patient care through innovative technology use. We argue that a new health care professional, the Technical Physician, should be trained to have the expertise to translate medical technology use into improved patient-specific procedures.
\end{abstract}

\section{Method}

An educational design model was followed, consisting of analysis, design, construction, implementation, and formative evaluation. Analysis of technology use in health care and the required expertise was conducted to derive the professional profile and core competencies. Adaptive expertise theory and research-based design form the foundation of the professional profile. Cognitive integration, self-directed learning, and technical medical design projects were selected as leading instructional principles.

\section{Evaluation}

The curriculum was implemented in 2003 in the Netherlands. Over 300 Technical Physicians have graduated since 2009.

Marleen Groenier

m.groenier@utwente.nl

1 Department of Technical Medicine, University of Twente, Enschede, The Netherlands

2 Department of Teacher Training, University of Twente, Enschede, The Netherlands
Internal evaluations showed that curriculum changes were necessary to (1) address the application of mathematical principles, (2) enhance reflection by increasing experience-based learning, (3) support development of adaptive expertise related to basic technical skills, and (4) aid faculty in translating their knowledge and skills to the Technical Medicine domain.

\section{Discussion}

We recommend a strong focus on supporting both faculty within the Technical Medicine program and the Technical Physicians in clinical practice with the translation of knowledge and skills between the technical and medical domains. Future research should systematically evaluate the design and effects of the Technical Medicine curriculum.

Keywords Technical physician · Patient safety · Research-based design · Adaptive expertise $\cdot$ Medical technology use

\section{Introduction}

The past century witnessed an explosion of new medical technologies that revolutionized health care. Medical technology is prominent in the top 10 most important innovations in medicine, according to a 2001 study by Fuchs and Sox [1]. These technological advancements provide opportunities to tailor such technologies to patient-specific needs. Examples are preoperative planning based on $3 \mathrm{D}$ reconstructions of the anatomy and patient-tailored dose regimes in chemotherapy. However, the World Health Organization [2] as well as the Dutch Health Care Inspectorate [3] has concluded that health 
care organizations and professionals are often insufficiently aware of the risks associated with medical technology use. Inappropriate use of medical technology by untrained professionals leads to inefficient health care at best, or adverse events at worst $[2,3]$. The Dutch government recognized the pressing need for health care professionals with specific technical medical expertise early on and approved the startup of a Technical Medicine curriculum in 2003. In this article, we first present an analysis of the developments leading to new and accountable use of technology in health care. Subsequently, we describe how we used its outcomes as input for the design and formative evaluation of a Technical Medicine curriculum aimed at educating a new health care professional, the Technical Physician, who can deliver complex, high-tech health care services.

Adequate implementation of new medical technology requires that health care professionals do not merely follow a manual and mindlessly apply this technology. To guarantee patient safety, these professionals should have the expertise to tailor medical procedures involving technology to the individual patient when necessary and not act as passive vehicles for the technology [4]. Subtle or unintended variations in the application of medical technology can have serious adverse consequences for an individual patient [4-6]. Safe use of medical technology depends on a health care professional's ability to assess the consequences of these variations for an individual patient [7]. In the following section, we describe our analysis of medical technology use in health care and identify factors that contribute to unsafe use of medical technology.

\section{Analysis}

\section{Medical Technology (Mis)use}

Medical technology is defined by "the techniques, drugs, equipment, and procedures used by health care professionals in delivering medical care to individuals, and the systems within which such care is delivered" (p. 4) [8]. This definition includes various applications of technology and refers not only to diagnostic procedures, therapies, and drugs, among other things, but also to medical devices such as instruments, appliances, software, or other artifacts. In this article, we adopt this broad definition of medical technology.

The rapid, continual innovation of medical technology offers opportunities for more effective and efficient health care. Inappropriate use of medical technology can be traced back to (1) the technology itself, (2) the medical technology approval process, and (3) the user. First, medical technology is extremely diverse. It is diverse in the type of mechanisms involved, the disciplines from which the technology originates, the degree of complexity, and the practical applications. Many medical devices have emerged not from clinical research but from technologies developed in other areas and meant for other purposes. Technologies such as lasers, magnetic resonance imaging, and navigation devices originated from physics and were intended for military use or space aviation [2]. The success of technology transfer from research or industry to clinical practice depends on many factors; simply explaining the technology's benefits to clinicians is not enough [6]. Technology is often presented as a solution, but without a proper understanding of important issues related to the user or the context in which the technology will be used [6]. An additional problem associated with this inadequate use is the so-called science push, a key characteristic of linear models of research-practice relationships [7]. Central to these models is the need to make research findings conceptually and physically accessible through their translation into guidelines, protocols, and/or technology, with an emphasis on implementing the solution instead of defining the problem.

Second, most medical technologies are not adequately assessed for specific health care applications. The Food and Drugs Administration of the USA and the European Commission in Europe require that the validity of each medical device is assessed before applying it in clinical practice [9]. Furthermore, in the Netherlands, hospitals have signed an agreement to guarantee safe use of technology by providing adequate training [10]. However, many medical devices are not used as intended or remain unused because of inadequate design, a lack of infrastructure, and insufficient information regarding maintenance $[4,11]$.

Third, human factors are one of the principal causes of errors in the use of medical technology $[4,5,12]$. Medical technologies are increasingly based on complex technological principles, often hidden from the user, which can apparently lead to errors.

Based on the previous analysis, we see a gap between the development of high-tech medical technology and the expertise needed to use it safely with individual patients. Engineering experts are responsible for the development and dissemination of medical technology, but are not trained to assess the effects of technology on the functioning of the human body. Medical experts adopt and use the medical technology developed by engineers, although they cannot be expected to fully understand the technological principles of medical technologies or to adequately assess the consequences of variations in the use of specific medical technologies. Engineering science is characterized by understanding the working mechanisms underlying natural or technical phenomena. Modeling such working mechanisms is a powerful tool in engineering, although modeling also implies a certain amount of simplification and elimination of noise. Medical technology that is based on these models developed by engineers is, in a sense, limited, because information might be lost, filtered away as noise. However, this noise often contains relevant 
patient-specific information that differs from patient to patient. Therefore, for health care professionals to understand how to cope with "noise," viewed from an engineering perspective, requires an understanding of both the underlying technological principles and the underlying principles of the functioning of the human body.

\section{Technical Medical Expertise}

Traditionally, medical problems are defined as diagnostic or treatment selection problems, also called categorization problems [13]: what is the diagnosis for this patient? Which treatment is most effective given this patient's condition? Knowledge about concepts and their interrelations is required to solve these problems adequately [14]. Clinicians learn to find regularities in patterns of features and interpret them. Over the years, this repeated solving of categorization problems results in the development of illness scripts, a specific type of knowledge representation [15]. Illness scripts allow clinicians to make quick and, most of the time, accurate decisions based on pattern recognition processes [16].

The problems that clinicians encounter when applying new or existing medical technology are of a different kind; these problems are complex and non-traditional. Technology offers solutions that require clinicians to adequately analyze and define the problem and design a treatment in which these solutions are embedded. Such problems can be described as design problems: solutions to these problems take the form of new plans, protocols, or artifacts [14]. Solving design problems is fundamentally different from traditional medical problem-solving, according to Goel and Pirolli [17]; it differs in the steps and the underlying knowledge representation needed to solve the problem. To solve design problems, knowledge about concepts and interpretations of these concepts is required, that is, conceptual knowledge [14]. Not only does the problem solver need an understanding of the underlying principles used, he or she also needs to know the functional requirements, namely, what is the designed solution supposed to do? Figure 1 illustrates the differences between a design problem and a traditional medical categorization problem.

Innovative, patient-specific applications of technology should be carefully designed and provided by a professional specifically trained to do so: the Technical Physician. Technical Physicians are trained to begin from the patient's perspective while also assessing technological possibilities and the consequences of medical technology use like an engineer. These professionals learn to understand medical technology use as the complex interaction between the human body and the technologies' underlying principles; they acquire the ability to translate knowledge and skills between the technical and medical domains. They accomplish this not by traditional, one-directional knowledge transfer from the technical to the medical domain, but act more like engineers by integrating the two domains when analyzing medical problems (diagnosis) and designing medical solutions (treatment).

Previous research has suggested that superior or expert performance is only possible in one particular domain [18, 19]. In general, expertise comes with great advantages, such as rapid detection of relevant information, successful selfmonitoring, effective problem-solving, and generation of the most satisfactory solutions [20]. However, there are also drawbacks to being an expert [20]. Research has shown that expertise is domain-specific, such that experts do not excel in domains in which they have no experience (see, e.g., Joseph and Patel [21]). In certain situations, expert clinicians might therefore apply pre-existing knowledge to non-routine or unfamiliar situations without the ability to see new possibilities or greater complexity; they are "routine" experts $[22,23]$ at solving categorization problems.

\section{Adaptive Expertise}

Solving design problems, which we recognize to be similar to engineering problem-solving, requires individuals to acquire other qualities and expertise. These individuals need to be able to transfer their knowledge to novel situations at the right time and in the right way; they are "adaptive experts" [24]. This successful transfer depends on an abstract knowledge representation that includes the interrelationships between core concepts $[25,26]$. Furthermore, a key factor seems to be that individuals engage in a thorough search for solutions, which implies that adaptive experts have a certain attitude towards problem-solving that other experts lack. Adaptive experts are characterized by the ability to flexibly transfer knowledge and skills to infrequent and non-routine situations and a positive attitude towards creating knowledge, which makes them different from other experts [24, 27].

Current medical practice with its high rates of technological change requires professionals who can successfully adapt to ongoing technological changes, that is, adaptive experts [26]. Palonen et al. [28] argue that adaptive expertise is most important in emerging fields. In technical medicine, an emerging field, professionals solve design problems at the intersection of the technical and medical domain, which requires effective transfer of knowledge and skills between these domains. Adaptive experts transfer what they have learned to new situations, adapt flexibly to different task conditions. and demonstrate satisfactory performance for infrequent or non-routine problems [24, 29].

\section{Research-Based Design}

Design problems also require a specific problem-solving approach that is characterized by creativity, analysis, and synthesis in order to result in an affordable solution [17]. These characteristics, creativity, analysis, and synthesis, are 
Fig. 1 Example of a categorization problem and a design problem in medicine

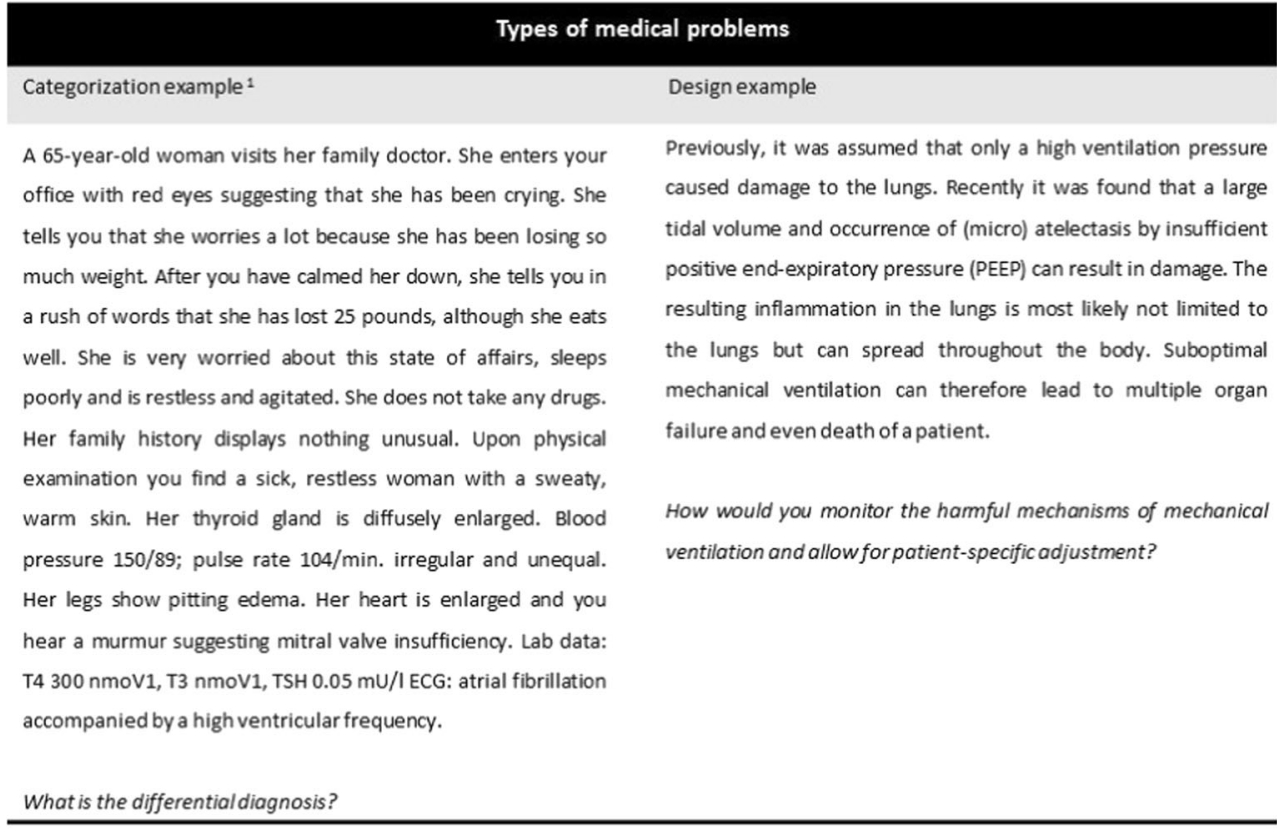

${ }^{1}$ Example from Boshuizen HPA, Van der Vleuten CPM, Schmidt HG, Machiels-Bongaerts M (1997) Med Educ 31:115-121. embedded in scientific evidence from the technical and medical domain. Therefore, we give the name "research-based design" to this "research-driven" design approach. Through applying the designed solution, relevant and usable knowledge is developed. It is a systematic problem-solving process that defines the problem, assesses the needs through reviewing previous studies and epidemiological evidence, designs a solution, has clear research goals that result in observable and evaluative outcomes, and is grounded in theory [30].

This research-based design practice brings research and practice closer together through having academic researchers work directly together with clinical practitioners in designing technical medical solutions for medical problems. Engaging practitioners in the co-creation of new knowledge, which is common in design research projects, is a powerful process for promoting the uptake and use of new insights among participants [31]. This research-based design model has the potential to become increasingly important for the medical disciplines, insofar as it can be introduced to increase the robustness of the practices of professional technical medical designers and contribute to practice-based theory building in the arena of medical technology and its procedures. Moreover, the model prescribes starting out with analysis to define the problem for which a solution will be designed. This engineering approach fits well with the appropriate and deliberate use of technology for solving medical problems.

In summary, Technical Physicians work on design problems in clinical practice that involve medical technology. Therefore, they need to understand both the functioning of the human body and the technology. As scientists working in clinical practice, in close collaboration with other health care professionals and with the goal of creating relevant and re-usable knowledge, they should be research-based designers. As practitioners in clinical practice, they also need technical medical skills, including the skills to perform reserved procedures, that is, procedures that only a licensed physician is legally allowed to perform according to the law in the Netherlands, and must display appropriate professional behavior. To become adaptive experts, Technical Physicians should be able to critically evaluate their decisions and actions with the patient's welfare in mind and to adjust their behavior accordingly. As adaptive experts, they need the cognitive flexibility to come up with appropriate responses to novel situations and to review multiple perspectives when considering solutions to new problems. These specific features of the problem-solving approach of Technical Physicians, together with the key characteristics of Technical Physicians, were translated and integrated into a Technical Medicine curriculum.

\section{Becoming a Technical Physician: Design of the Technical Medicine Curriculum}

In designing the curriculum, we followed a common and generic design model by Gustafson [32], which includes analysis, design, implementation, and evaluation phases. Author HM was responsible for designing the curriculum. Application of the design model began with a needs assessment and was followed by design of the curriculum, based on a compilation of competencies derived from a professional profile, together with instructional principles. This meant that 
the construction of the program occurred while implementation considerations and evaluation of initial ideas were continuously taken into account. In this article, we emphasize the formative evaluation of the curriculum. Formative evaluation pertains to the improvement of the curriculum. A curriculum is assessed during its development or early implementation to provide information about how best to revise and modify it for further improvement. In contrast, summative evaluation is performed at the end of a design cycle, and findings are meant to check whether the objectives of the program have been met. Further, summative evaluation is aimed at a periodic review of long-term progress on major objectives.

For the needs assessment, a broad analysis was performed to establish the desired professional profile, along with the technical medical qualities and characteristics described above, also included as competencies. A literature review was conducted on medical, technical, and engineering expertise, which we have discussed above in the "Analysis" section. Furthermore, interviews with subject matter experts and stakeholders were held. We aimed for a diverse group of experts and stakeholders to achieve a broad and complete perspective on technical medical expertise. Academic experts were interviewed, as well as stakeholders from teaching and peripheral hospitals. The subject matter experts were mechanical engineers, electrotechnical engineers, physicists, pathologists, internal medicine specialists, physiology experts, anatomy experts, and psychologists. The stakeholders were clinical specialists, namely, surgeons, neurosurgeons, intensive care specialists, pulmonologists, electrophysiologists, and neurologists. In the interviews, subject matter experts were asked to reflect on the following questions: (1) What technology do you use and fully understand? (2) What technology do you not understand and why not? (3) How do you define and analyze a problem from your professional domain? Engineers were additionally asked to describe their design approaches.

\section{Professional Profile}

The professional profile defines the requirements and qualities necessary to be a competent Technical Physician as a solver of design problems. These requirements and qualities are often expressed as competencies: an integration of knowledge, skills, and professional attitude [33]. The professional profile of the Technical Physician also describes the future field, tasks, and responsibilities of the Technical Physician.

Based on the needs assessment, the professional profile specified that
"A Technical Physician is a health care specialist who is competent in medical subjects, specific engineering and computer science subjects and is able to integrate these domains for adequate diagnosis and treatment in a health care setting. The Technical Medical domain con- cerns the analysis and identification of medical prob- lems that results in the design and implementation of a solution for these problems based on knowledge of and insight into pathophysiological and technological concepts."

Figure 2 indicates the position of a Technical Physician on the continuum from Physician to Engineer and illustrates the differences between solving design problems, which aims at innovating by designing (Technical Physician) and solving traditional medical problems, which aims at innovating by applying (Physician). Technical Physicians apply engineering problem-solving strategies to design safe diagnostic or therapeutic procedures involving technology and tailored to the individual patient. More specifically and formally, to apply these patient-specific procedures in direct patient care, Technical Physicians need to be legally licensed to practice medicine independently.

\section{Core Competencies}

Relevant competencies were derived from the defined professional profile, based on extensive interviews with subject matter experts and stakeholders, as well as from the literature review on medical, technical, and engineering expertise that was described in the "Analysis" section above. From the literature review, the two theoretical constructs of adaptive expertise and research-based design became the foundation of the competency profile and were used to group the relevant competencies. Table 1 presents an overview of the competencies in relation to the two theoretical constructs.
Fig. 2 The position of the Technical Physician in the health care continuum

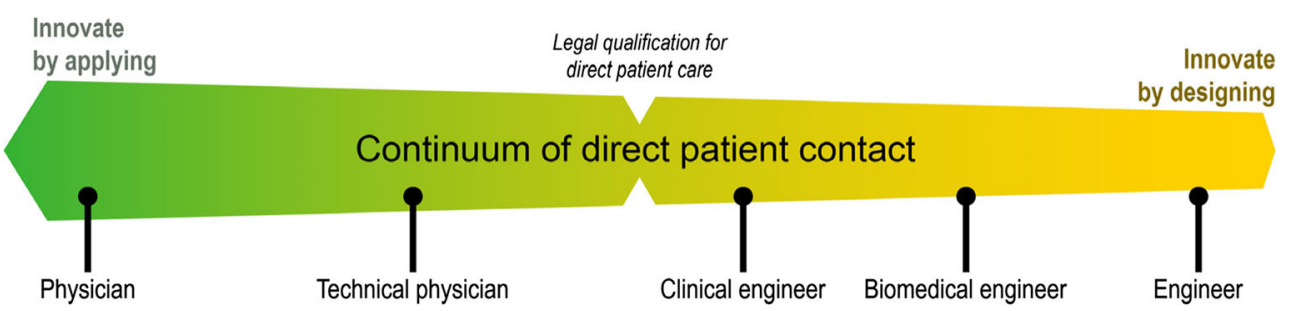


Table 1 Overview of technical medical competencies

Competencies
$\begin{aligned} & \text { Adaptive } \\ & \text { expertise }\end{aligned}$
$\begin{aligned} & \text { Research- } \\ & \text { based design }\end{aligned}$
Discipline of Technical Medicine
The Technical Physician is familiar with the
most recent scientific knowledge and able
to expand his/her knowledge by studying.
Research and design
The Technical Physician is able to acquire
new scientific knowledge and design new
diagnostic methods and treatment plans by
doing research.
Medical technical performance
The Technical Physician is able to apply
medical technology, aimed at innovation,
in the diagnostic and therapeutic process,
based on integration of knowledge, skills,
planning, and reflection.
Scientific thinking
The Technical Physician uses a systematic
approach, based on the empirical cycle and
characterized by the development and use
of theories, models, and integrated
interpretations, and has a critical attitude
and an understanding of science and
technology.
Intellectual performance
The Technical Physician is able to reason,
reflect, and pass judgment. These skills are
acquired in a domain-specific technical
medical context but transfer to other do
mains.
Professional behavior
The Technical Physician has a personal work
style that reflects the profession's norms
and values. This concerns coping with
tasks, others, and oneself.
Situational competence
The Technical Physician is able to integrate
the societal and organizational situation
into his/her medical technical
performance.

\section{Instructional Principles}

Cognitive integration, self-directed learning, and technical medical design projects are the three leading principles for instruction that directs and supports the acquisition of the core competencies. These instructional principles stimulate the development of adaptive expertise and research-based design skills.

\section{Cognitive Integration}

First and foremost, the curriculum aims to foster understanding not only of how technology and the human body function but more importantly of why they function as they do. Understanding why relates to a learner's conceptual knowledge, that is, meaningfully structured knowledge about relationships between concepts, which is associated with adaptive expertise [25]. Cognitive integration guides the presentation of information in an integrated way and stimulates the development of conceptual knowledge [34]. Cognitive integration has been successfully used in medical education to improve diagnostic reasoning by presenting biomedical and clinical science knowledge in a schematic, structured manner [35]. See Box 1 for an example from the Technical Medicine curriculum.

\section{Box 1 Cognitive integration in the Technical Medicine curriculum}

Technical Medicine students learn about the human body in both the healthy and diseased state in subjects focused on all of the subsystems of the human body, such as the respiratory, musculoskeletal, and neural systems. The same schematic framework is used to present information about the specific subsystem in each of the subsystem subjects: the anatomy, the physiology, the pathophysiological core concepts, and the medical technological core concepts derived from their applications. Furthermore, core technological concepts and technological developments are taught in basic science subjects such as mathematics, physics, chemistry, and engineering subjects such as mechanical engineering, electrical engineering, and computer science.

\section{Self-Directed Learning}

The curriculum aims at the development of Technical Physicians who demonstrate conscious competence: professionals who are aware of their own knowledge and capabilities in a health care setting. Self-directed learning contributes to this developmental process, because students must be aware of their learning needs, formulate their own learning plans, and evaluate their own learning process [36]. In learning environments aimed at self-directed learning, students are responsible for building their own knowledge [25, 37]. Adaptive expertise development is stimulated by learning environments that allow students to build their own knowledge by exploring, discovering, and developing an individual solution strategy in new situations $[25,37]$. In Box 2, two examples of self-directed learning in the Technical Medicine curriculum are described.

\section{Box 2 Self-directed learning in the Technical Medicine curriculum}

Example 1 Self-directed learning in projects

Students' self-directed learning processes are explicitly promoted in the projects in the bachelor's program. During projects, feedback from various subject matter experts, such as clinicians, engineers, and mathematicians, is used to stimulate the ability to explore problems from multiple perspectives. This feedback is aimed not only at task performance but also at students' problem-solving processes. Students systematically reflect on both, guided by peer tutors to further stimulate development of a specific technical medical problem-solving strategy.

\section{Example 2 Self-directed learning in clinical rotations}

Students write individual learning plans as part of the clinical rotations during the master's program. Afterwards, students are assessed on their ability to self-evaluate and critically reflect on their learning process in a written report. Students discuss their technical medical competency development and new learning goals with their mentor (psychologist) individually after each clinical rotation. 


\section{Technical Medical Design Projects}

A recent review by Carbonell et al. [25] on adaptive performance stressed the importance for adaptive expertise development of being confronted with novel situations and learning new tasks. The curriculum aims to have students gradually adopt a specific technical medical problem-solving strategy, reflecting the characteristics of adaptive expertise and research-based design. Various authentic design tasks for diagnostic or therapeutic problems of increasing complexity are used to practice solving technical medical problems; see Box 3 for an example from the Technical Medicine program. These projects aim to support development of both adaptive expertise and research-based design skills [38].

\section{Box 3 Design project in the Technical Medicine curriculum}

Currently, different methods are used to diagnose prostate cancer; each has its advantages and limitations. One of these methods is transrectal ultrasound (TRUS) guided biopsy. TRUS is at the moment the gold standard for diagnosing prostate cancer. However, this method is also limited. The target area of the prostate cannot easily be reached with a needle, and the prostate can move or deform as a result of the clinician's hand movements. Your assignment is to describe a design that overcomes the current limitations of TRUS-guided biopsy in diagnosing prostate cancer.

\section{Curriculum Structure}

The admission procedure for Technical Medicine is on a par with the admission procedure for medical schools in the Netherlands, consisting of a qualitative competitive selection procedure [39]. Once accepted, the student begins a 6-year curriculum of integrated technical medical knowledge and skills, reflecting the Dutch medical curriculum of three undergraduate years (bachelor's degree) and three graduate years (master's degree), see Fig. 3. In the undergraduate years, students do two 2-week internships that are focused on the patient perspective and nursing aid work in the first year and on the medical specialist in the third year. In the two final graduate years of Technical Medicine, students do four 10-week clinical rotations and one 40 -week clinical rotation at both teaching and non-academic hospitals.

An important part of the curriculum is the technical medical skills component. Technical Physicians need to be able to perform some of the reserved procedures, as well as to demonstrate appropriate professional behavior. Scherpbier et al. [40] distinguished four types of medical skills: laboratory skills, such as simple diagnostic techniques relevant for general practice, physical examination, communication skills, and therapeutic skills, such as giving injections and suturing. Skills education in Technical Medicine is different from that in the medical schools. Laboratory skills for general practice are deemed to be not relevant for Technical Physicians. Physical examination skills to support diagnosis are less relevant because Technical Physicians use technology to diagnose patients; for example, they might use automatic detection algorithms, rather than physical examination. Physical examination is taught, but this is not to practice clinical reasoning. Rather, this serves as a tool to assess students' understanding of clinical cases and disease manifestations. Communication skills are taught in technical medical undergraduate education, similar to what is taught at the medical schools, because Technical Physicians work as part of the medical team in the hospitals and interact with patients. Reserved procedures relevant for Technical Physicians are taught in our simulation center, the Experimental Centre for Technical Medicine.

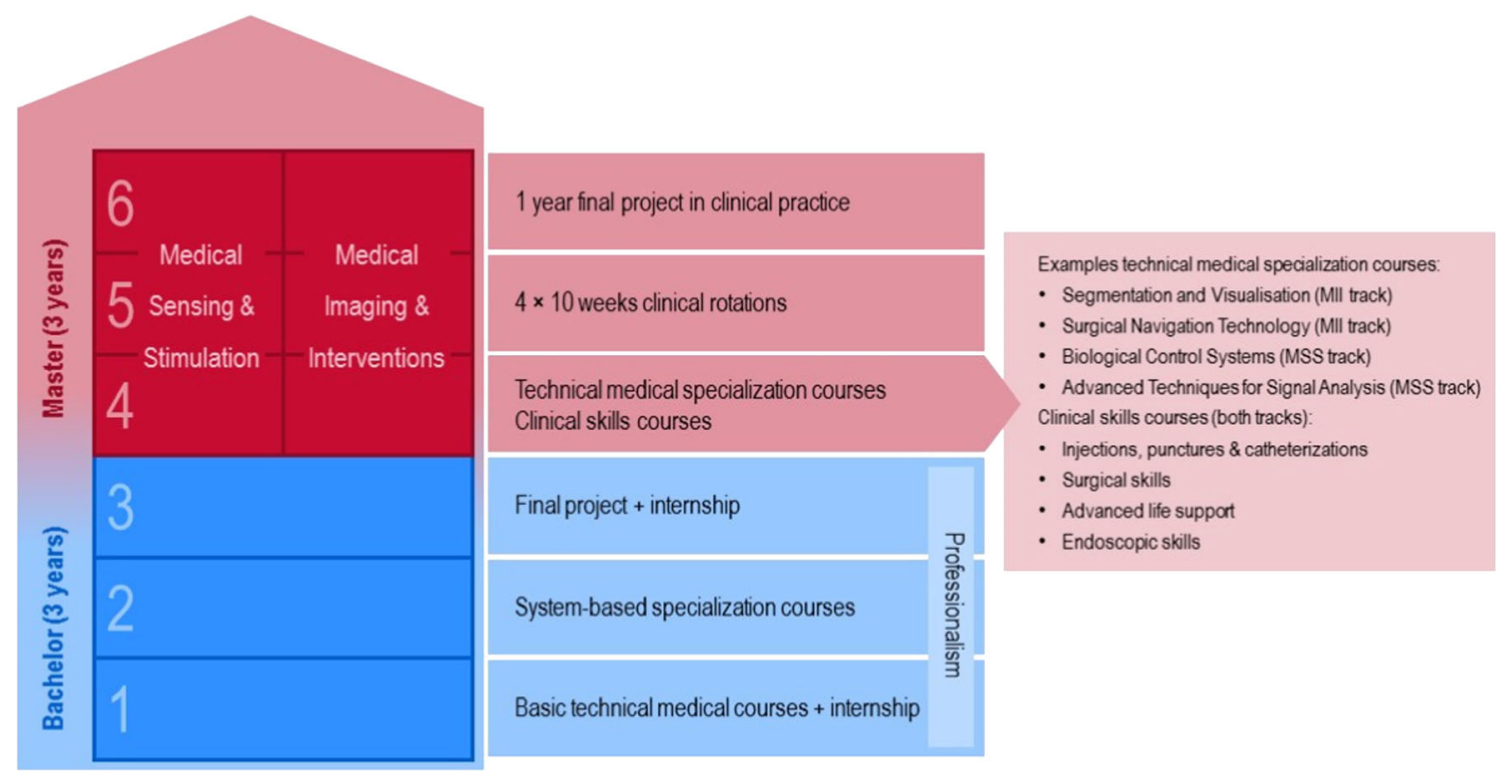

Fig. 3 Structure of the bachelor's and master's degree programs of Technical Medicine 
These procedures are technical surgical skills, catheterization and endoscopies, punctures and injections, radiation hygiene, elective cardioversion, defibrillation, and lithotripsy. Simulation-based training and assessment of communication and technical medical skills are integrated into technical medical undergraduate, graduate, and post-graduate education. In contrast to the still-common practice of the apprenticeship model in medical education, technical medical students must demonstrate proficiency in the reserved procedures in a simulated environment before they are allowed to practice them on actual patients during their clinical rotations.

Furthermore, the curriculum aims to educate Technical Physicians who are conscious of their professional responsibility. Technical Physicians need a venturesome, entrepreneurial professional attitude, which in this context means daring to think outside the box, inventing new ways to solve clinical problems by innovative use of technology, and having the skills to translate new ideas into clinical practice. Patient safety is of the utmost importance when medical technology is used in clinical practice, and therefore, it is at the core of a Technical Physician's professional responsibility. Professional responsibility regarding patient safety encompasses insight into one's own capabilities and level of proficiency, insight into one's relationship with others (e.g., patients or colleagues), and insight into one's moral and societal responsibility regarding the use of medical technology.

\section{Formative Evaluation of the First Dutch Technical Medicine Curriculum}

As discussed above, the next step in designing a Technical Medicine curriculum was formative evaluation. The curriculum was implemented in 2003 in the Netherlands. Since 2009, over 300 Technical Physicians have graduated and entered the health care field, see Table 2. The Dutch government acknowledged the new discipline by giving permission to start the program and by changing the law to recognize Technical Physicians as competent to treat their own patients. In 2009,

Table 2 Figures for technical medical education in the Netherlands

\begin{tabular}{lr}
\hline Dutch population & $17 \mathrm{mln}$ \\
\hline Number of graduated Technical Physicians & 310 \\
Number of Technical Medical PhD students & 230 \\
Number of clinical fellowships & 12 \\
Number of technical medical curricula & 2 \\
Total yearly enrollment of new students & 230 \\
Total number of Technical Medical students & 800 \\
Male/female ratio & $4: 6$ \\
\hline
\end{tabular}

the Dutch Society for Technical Medicine was founded (see http://www.nvvtg.nl/). In 2016, the society organized the sixth annual Technical Medicine conference, covering relevant topics such as modern surgical training and patient safety, big data in health care, and neuromonitoring at the ICU.

The Plan-Do-Check-Act cycle was used to identify strengths and weaknesses of the program. Student evaluations that were carried out prompted numerous improvements, and stakeholder assessments led to fine-tuning of the program and explicated the relationship between the Technical Medicine program and medical practice.

Based on internal evaluations, four observations resulted in significant changes to the curriculum. First, students reported that they did not use the mathematical principles taught because they did not know how and when to apply them. In response, increased attention was directed to the clinical application of mathematical principles rather than demonstrating proof of a mathematical principle. Second, students experienced difficulties with one of the professional behavior competencies, critical reflection, especially in the bachelor's program. The curriculum was redesigned to teach critical reflection through experience-based learning by having students write reflection reports about their internships and medical interviewing skills. Students are also now asked to reflect on their internships while taking a specific perspective. In the internship in year 1, they focus on the patient's perspective on health care, and in year 3 on the physician's perspective. Third, the skills training program was redesigned to support adaptive rather than routine expertise development. This change mainly concerned teaching of the basic technical skills, such as suturing, injections, and intubation. Our goal is for Technical Physicians to further improve clinical interventions that rely on these basic skills; therefore, we reasoned that increased skill automation is not required and might even hinder the process of designing innovative interventions. Fourth, technical and medical faculty reported difficulties in translating their knowledge and skills to a completely new domain, that of Technical Medicine. Faculty were then given support in defining the core concepts of their domain that were considered relevant for Technical Physicians and in integrating these core concepts with other domains such as anatomy, physiology, pathophysiology, and technology.

Stakeholder assessments revealed optimism among members of the medical community about the introduction of Technical Physicians in health care:

"These new professionals are important members of our medical staff. Patient-specific mechanical ventilation and quality of care have improved considerably." Prof. Dr. Van der Hoeven, Intensive Care Unit, RadboudUMC

"The combination of technology, physiology and pathophysiology contributes to improved, more efficient and 
safer health care." Prof. Dr. ir. Van Putten, Clinical Neurophysiology, Medisch Spectrum Twente

"I am convinced that Technical Physicians will play an important role in future developments in Medicine; therefore, it is our goal to add these professionals to our staff." Prof. Dr. De Leij, Dean Research, UMCG

Furthermore, stakeholders are directly involved in workplace-based assessment of Technical Physicians' clinical performance. Currently, Technical Physicians are required to certify their clinical performance, which includes an evaluation by a medical specialist. This evaluation consists of not only an assessment of performance of clinical skills but also an assessment of the effectiveness of a procedure performed by a Technical Physician, that is, a description of the problem, methods, and results. The Dutch Society for Technical Medicine and the management team of the Technical Medicine program meet on a regular basis to evaluate the outcomes and discuss possible consequences for the Technical Medicine program.

\section{Conclusion and Discussion}

In this article, we demonstrated the need in health care for a type of medical professional who is able to translate medical technology into innovative, safe, and effective patient care. This translation requires specific competences related to adaptive expertise and research-based design. Technical Physicians complement medical expertise with specific technical medical expertise and possess the required competencies to treat their own patients in a safe way.

We argued that technological developments and their implications for individualized patient care have become even more prominent in health care. However, as Hofmann [41] stated: "Technologies are widely used without evidence of their effectiveness, safety, and efficiency." (p. 1) Uncritical use of technology will only contribute to medical errors. We agree with Hofmann that reflection is needed, but would add that optimal implementation of medical technology requires more than reflection; it requires specific technical medical expertise. For this reason, the educational program in Technical Medicine was designed and implemented.

In the Netherlands, hospitals and industry recognized that the lack of proper training in medical technology needed to be addressed [10]. In 2011, they signed a covenant in which they agree to take the responsibility for adequate training of health care professionals in the use of medical technology. Although there is increasing awareness of the problems associated with unskilled professionals using medical technology, such an agreement does not fully address the mismatch of expertise domains identified in this article. Not only is proper training with existing medical technology lacking, health care professionals in general do not have the technical medical expertise necessary to tailor clinical procedures involving medical technology to individual patients' needs. Technical Physicians have successfully bridged this gap between the medical and technical expertise domains.

Several lessons emerged from our experience that may help others in designing a curriculum for health care professionals in a high-tech health care environment. We found that faculty professional development is a crucial element in translating knowledge and skills from one domain to a completely new domain. Faculty need to be consciously aware that they are role models for the students and need to clarify how the core concepts of their particular domain are relevant to the domain of Technical Medicine.

We also learned that the instructional principle of cognitive integration is not only essential for delivering and integrating the content of the curriculum, it is also a guiding principle for the Technical Physician's problem-solving process. An analysis of anatomy, physiology, pathophysiology, and technology is the starting point for each Technical Physician's problem-solving process and a defining characteristic of their expertise.

Finally, we found that the introduction of the Technical Physician was facilitated by a thorough understanding of the organizational structure of the health care system and the roles different health care professionals have in that system. Acceptance of this new type of professional with a specific technical medical expertise depends on the added value they have in improving the quality and safety of high-tech health care.

Inappropriate or suboptimal use of medical technologies could result in costly and inefficient health care or even adverse events $[2,3]$. We argued that patient care can be improved by innovative use of current medical technology, if it is used by technical medical experts. We described the development of a new health care professional with a specific technical medical expertise, the Technical Physician. Technical Physicians think and act from the perspective of the individual patient when using medical technology to solve clinical problems. They apply engineering problem-solving strategies in clinical practice to design safe and individualized diagnostic or therapeutic procedures.

The technical medical curriculum aims to prepare Technical Physicians for the challenging tasks they face in bringing medicine and engineering together. We are convinced that at the end of their graduate education, they are able to fly instead of merely to run, as was nicely stated by Rowland [42] in his reflection about educating designers: "Have we been teaching people to walk, expecting them to develop the ability to run, when the job requires them to fly? Running is not flying. It requires a very different set of muscles and skills." (p. 36). 


\section{Future Directions}

Continuing technical medical education is the next step in technical medical curriculum development. Further professional development through credentialing and lifelong learning is as important for Technical Physicians as for other health care professionals. Clinical fellowships and $\mathrm{PhD}$ positions require Technical Physicians to continue their education after graduation. Advanced technological courses should be provided for clinical fellows, as their clinical experience will take place in practice. $\mathrm{PhD}$ students should be required to keep their clinical experience up-to-date, which could take place in dedicated simulation centers.

Curriculum designers and stakeholders should be aware that expertise is domain-specific; hence, explicit translation between the different domains is continually required, even after successful implementation of a new curriculum. This translation between domains is also required from a Technical Physician, who is working in a multidisciplinary field together with clinicians, engineers, health care managers, and many others. Therefore, both lecturers in the technical medical domain and Technical Physicians should be equipped with an explicit problem-solving strategy that helps them translate between domains.

An important question remains as to whether Technical Physicians actually do use medical technology effectively and efficiently while ensuring patient safety. To answer this question, structured and systematic evaluation of the design and effects of the technical medical curriculum is the next step.

Acknowledgements We would like to thank the three anonymous reviewers who have thoroughly read the manuscript and provided us with valuable feedback and suggestions for improvement.

\section{Compliance with Ethical Standards}

Conflict of Interest The authors declare that they have no conflict of interest.

\section{Funding None.}

Open Access This article is distributed under the terms of the Creative Commons Attribution 4.0 International License (http:// creativecommons.org/licenses/by/4.0/), which permits unrestricted use, distribution, and reproduction in any medium, provided you give appropriate credit to the original author(s) and the source, provide a link to the Creative Commons license, and indicate if changes were made.

\section{References}

1. Fuchs VR, Sox HC Jr. Physicians' views of the relative importance of thirty medical innovations. Health Aff. 2001;20:30-42.

2. World Health Organization. Medical devices: managing the mismatch: an outcome of the priority medical devices project. Geneva: World Health Organization; 2010.
3. Health Care Inspectorate (2008) Risico's van medische technologie onderschat [risks of medical technology underestimated]. The Hague, The Netherlands. Downloaded from: http://www.igz.nl/ a c t u e e $1 / \mathrm{n}$ i e u w s / medischetechnologiebiedtgrotekansenmaarrisicosonderschat.aspx.

4. Cook RI, Woods DD. Adapting to new technology in the operating room. Hum Factors. 1996;38:593-613.

5. Carthey J, de Leval MR, Reason JT. The human factor in cardiac surgery: errors and near misses in a high technology medical domain. Ann Thorac Surg. 2001;72:300-5.

6. Dawson S. Never mind solutions: what are the issues? Lessons of industrial technology transfer for quality in health care. Qual Health Care. 1995;4:197-203.

7. Hoffman RR, Ward P, Feltovich PJ, DiBello L, Fiore SM, Andrews DH. Accelerated expertise: training for high proficiency in a complex world. New York: Psychology Press; 2014.

8. Office of Technology Assessment. Development of medical technology. Washington DC: U.S. Government Printing Office, OTA$\mathrm{H}-34 ; 1976$.

9. Kessler L, Richter K. Technology assessment of medical devices at the Center for Devices and Radiological Health. Am J Manag Care. 1998;4:SP129-35.

10. Nederlandse Vereniging van Ziekenhuizen, Nederlandse Federatie van Universitair medische centra, Revalidatie Nederland (2011) Convenant Veilige toepassing van medische technologie in het ziekenhuis. [Covenant Safe application medical technology in the hospital] Utrecht, The Netherlands. Downloaded from https://www. rijksoverheid.nl/documenten/convenanten/2011/12/23/convenantveilige-toepassing-van-medische-technologie-in-het-ziekenhuis.

11. Amoore J, Ingram P. Learning from adverse incidents involving medical devices. Nurs Stand. 2003;17:41-6.

12. Kohn LT, Corrigan JM, Donaldson MS. To err is human: building a safer health system. Washington DC: National Academy Press; 2000.

13. Charlin B, Tardif J, Boshuizen HP. Scripts and medical diagnostic knowledge: theory and applications for clinical reasoning instruction and research. Acad Med. 2000;75:182-90.

14. Dijkstra S, van Merriënboer JJ. Plans, procedures, and theories to solve instructional design problems. In: Dijkstra S, Seel N, Schott F, Tennyson RD, editors. Instructional design international perspective: solving instructional design problems, vol. 2. Mahwah: Lawrence Erlbaum Associates; 1997. p. 23-43.

15. Schmidt $\mathrm{H}$, Boshuizen $\mathrm{H}$. On acquiring expertise in medicine. Educ Psychol Rev. 1993;5:205-21.

16. Elstein AS, Schwarz A. Clinical problem solving and diagnostic decision making: selective review of the cognitive literature. BMJ. 2002;324:729-32.

17. Goel V, Pirolli P. The structure of design problem spaces. Cogn Sci. 1992;16:395-429.

18. Chi MT, Glaser R, Farr MJ, editors. The nature of expertise. Hillsdale: Lawrence Erlbaum Associates; 1988.

19. Schraagen JM. How experts solve a novel problem in experimentaldesign. Cogn Sci. 1993;17:285-309.

20. Chi MTH. Two approaches to the study of expert's characteristics. In: Ericsson KA, Charness N, Feltovich P, Hoffman R, editors. Cambridge handbook of expertise and expert performance. Cambridge: Cambridge University Press; 2006. p. 21-30.

21. Joseph G-M, Patel VL. Domain knowledge and hypothesis genenation in diagnostic reasoning. Med Decis Mak. 1990;10:3144.

22. Cooke M, Irby DM, O’Brien BC. Educating physicians: a call for reform of medical school and residency. San Fransisco: John Wiley \& Sons; 2010.

23. Mylopoulos M, Regehr G. Cognitive metaphors of expertise and knowledge: prospects and limitations for medical education. Med Educ. 2007;41:1159-65. 
24. Hatano G, Inagaki K. Two courses of expertise. In: Stevenson H, Azuma H, Hakuta K, editors. Child development and education in Japan. New York: WH Freeman; 1986. p. 27-36.

25. Carbonell KB, Stalmeijer RE, Könings KD, Segers M, van Merriënboer JJ. How experts deal with novel situations: a review of adaptive expertise. Educ Res Rev. 2014;12:14-29.

26. Kalyuga S, Renkl A, Paas F. Facilitating flexible problem solving: a cognitive load perspective. Educ Psychol Rev. 2010;22:175-86.

27. Mylopoulos M, Woods NN. Having our cake and eating it too: seeking the best of both worlds in expertise research. Med Educ. 2009;43:406-13.

28. Palonen T, Boshuizen HP, Lehtinen E. How expertise is created in emerging professional fields. In: Halttunen T, Koivisto M, Billett S, editors. Promoting, assessing, recognizing and certifying lifelong learning. Dordrecht: Springer; 2014. p. 131-49.

29. Novick LR, Holyoak KJ. Mathematical problem solving by analogy. J Exp Psychol Learn Mem Cogn. 1991;17:398-415.

30. Edelson DC. Design research: what we learn when we engage in design. J Learn Sci. 2002;11:105-21.

31. Ormel BJB, Pareja Roblin NN, McKenney SE, Voogt JM, Pieters JM. Research-practice interactions as reported in recent design studies: still promising, still hazy. Educ Technol Res Dev. 2012;60:967-86.

32. Gustafson KL. Instructional design tools: a critique and projections for the future. Educ Technol Res Dev. 2002;50:59-66.

33. van der Klink M, Boon J. The investigation of competencies within professional domains. Hum Resour Dev Int. 2002;5:411-24.
34. Kulasegaram KM, Martimianakis MA, Mylopoulos M, Whitehead CR, Woods NN. Cognition before curriculum: rethinking the integration of basic science and clinical learning. Acad Med. 2013;88: 1578-85.

35. Lisk K, Agur AM, Woods NN. Exploring cognitive integration of basic science and its effect on diagnostic reasoning in novices. Perspect Med Educ. 2016;31:1-7.

36. Birney DP, Beckmann JF, Wood RE. Precursors to the development of flexible expertise: metacognitive self-evaluations as antecedences and consequences in adult learning. Learn Individ Differ. 2012;22:563-74.

37. Bell BS, Kozlowski SW. Active learning: effects of core training design elements on self-regulatory processes, learning, and adaptability. J Appl Psychol. 2008;93:296-316.

38. Van Merriënboer JJ, Kirschner PA, Kester L. Taking the load off a learner's mind: instructional design for complex learning. Educ Psychol. 2003;38:5-13.

39. Ten Cate O. Medical education in The Netherlands. Med Teach. 2007;29:752-7.

40. Scherpbier A, Verwijnen G, Schaper N, Dunselman G, Van der Vleuten C. Vaardigheidsonderwijs nu en in de toekomst. [Skills education now and in the future] Tijdschrift voor Medisch Onderwijs. 2000;19:6-15.

41. Hofmann BM. Too much technology. BMJ. 2015;350:h705.

42. Rowland G. Educating the reflective designer. Educ Technol. 1992;32:36-44. 